this effect is unknown and findings are the opposite to those on serum corticosteroids in immobilized patients, which are significantly raised. ${ }^{2}$ There may be either reduced testicular response to gonadotrophins or decreased hypothalamus-pituitary gland activity.

It would seem that both extremes of physical activity have significant effects on serum androgens in men.-We are, etc.,

M. H. BRIGGS P. GARCIA-WEBB

Alfred Hospital, Thomas Cheung

Prahran,

Victoria, Australia

1 Chen, J., Zorn, E., Hallberg, M., and Wieland, R., Clinical Chemistry, 1971, 17, 581. Korpassy, A., Stoeckel, H., and Vecsei, P., Acta
Anaesthesiologica, Scandinavica, 1972, 16, 161.

\section{Doxycycline in Enteric Fever and Brucellosis}

SIR,-We have been familiar in the past 35 years in Egypt with enteric fever as well as brucellosis and their traditional treatment with chloramphenicol and chloramphenicol and streptomycin respectively.

During practice in the past two years in Nigeria we have been treating such cases with doxycycline. Recently we treated 20 cases suffering from either or both diseases. These patients had typical clinical manifestations and positive agglutination tests (for Salmonella typhi (5 cases), for Brucella abortus ( 5 cases), for both ( 6 cases), and for Salm. typhi and paratyphi B (4 cases), with rising titres. Defervescence was recorded on the fourth day of treatment on the average, together with marked amelioration of clinical symptoms. The patients were followed up for one month with no evidence of recrudesences or relapses.

The successful dosage of doxycycline hydrochloride was $200 \mathrm{mg}$ daily for four day followed by half this dose daily for another six or seven consecutive days (total 1,400 $1,500 \mathrm{mg}$ ). The dosage previously recommended was inadequate to bring about cure. There was neither any material side effect nor any change in the haematological picture.

Two patients with icterus, included in this series, showed rapid improvement in liver function as well as in their general condition. -We are, etc.,

\section{A. Z. SHAFEI}

General Hospital Ilorin,

W. S. LUKA

\section{Psychosurgery}

SIR,-We settled down to read with interest the recent discussion on ethics, rather contentiously entitled "Changing the Patient's Personality" (9 June, p. 594), only to be disappointed because much of the discussion showed little awareness of contemporary psychosuinery.

Dr. Henry Rollin in particular could easily have been speaking 30 years ago in presenting his views about psychosurgery. He may like to be reminded that the enormous vogue for standard leucotomy occurred largely during the 1940s, and Tooth and Newton ${ }^{1}$ described the results of over 10.000 such operations carried out up to 1954. This early operation was largely used in cases of schizophrenia, though it was noted on several occasions that affective psychoses responded much better. But in those days schizophrenia was the primary therapeutic problem and for many patients, the crude standard operation was probably preferable, with all its risks of serious side effects, to the continuation of chronic and severe psychological disturbance. As the Lancet ${ }^{2}$ has put it, "such was the enormous pool of psyohotic patients vegetating as chronic sick in the closed wards of mental hospitals, without effective drug control and without hope, that, when it became possible to help them in any way, this new method was taken up with more enthusiasm than caution, and with more teohnical skill than psychiatric or neurophysiological understanding."

With the advent of potent psychotropic drugs in the 1950s the use of psychosurgery declined greatly and the situation is now fundamentally different in two respects; firstly, psychosurgery is now only very rarely used for schizophrenia and, secondly, the operations have been considerably refined with the result that effects on the personality are rare and, where they occur, are usually of socially negligible effect. The title of the discussion thus prejudges the issue.

Psychosurgical operations have continued to be modified and one of the most recen techniques which has become the most frequently used is Knight's stereotactic subcaudate tractotomy, ${ }^{3}$ the clinical effects of which have been reviewed by Ström-Olsen and Carlisle ${ }^{4}$ and by Bridges et al. ${ }^{5}$ This has proved a valuable treatment for those few patients disabled by chronic depression obsessional neurosis, or anxiety whose response to routine treatments is temporary or inadequate. Effects on the personality depend to some extent on the criteria employed but they are certainly rare with this operation and where they occur they are mild. Probably the most serious side effects is that of epilepsy, occurring with an incidence of about $1 \%$, but patients are usually willing to accept this if relief is offered from chronic and disabling psychiatric symptoms.

Dr. Rollin states "I solemnly took a vow many years ago that under no ciroumstance would I ever recommend another [psychosurgical operation]. . . . To do a destructive operation on such an infinitely delicate and complex organ is like kicking some equally delicate and complex machine which is out of order. . . "This credo sounds rathe grand and just a bit idiosyncratic, but would be of little help to a chronically depressed and suicidal patient who has been able to obtain no relief from other forms of treatment. In addition it is a view that does not acknowledge the development of other treatments in medicine, often established empirically.

The most important aspect of the discussion concerned the use of psychósurgery for abnormal aggressive hehaviour where the ethics are so far totally uncharted. Knight's stereotactic tractotomy is most unlikely to be indicated in such cases so we have no experience in this unit of the problems involved. It would therefore have been instructive to learn the views of others had they got their ground work clearer first.-We are, etc.,

P. K. BRIDGeS JOHN R. BARTLETT

Geoffrey Knight Psychosurgical Unit, Brook General Hospital,

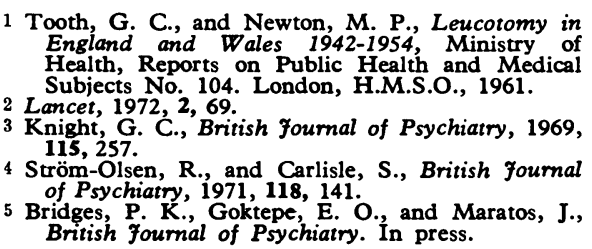

\section{American Medicine}

SIR,-It is regrettable that Professor L. J Witts in his Personal View (5 May, p. 299) should lend his prestige to propagating the myth of the "inferiority" of American medicine, and that apparently on the basis of reading one man's book on the subject. Does Professor Witts encourage his students to publish papers without experimental verification?

In 1970 I practised for five months as a locum consultant surgeon in England and worked in five provincial hospitals. In none of those hospitals was there a formal training programme for the residents such as is demanded in the U.S. In none of them did I find an intermittent positive-pressure breathing machine, whereas in the 200 -bed community hospital I practise in here there is a separate department of respiratory physiology so that I.P.P.B. and blood gas analysis are available day or night. You stated in a recent leading article (21 April p. 131) that $T-3$ and $T-4$ tests for thyroid function are not yet generally available (in the U.K.). In our hospital these tests are a matter of routine. In America general practitioners are everywhere included on hospital staffs, and though the independent family practitioner is not as common as formerly, our hospital has an outpatient department staffed by five family practitioners and open from 9 a.m. to 9 p.m. every day of the week.

Having practised in seven countries on four continents, I believe that the overall standard of medical care in the U.S. is the best I have seen, and that includes the U.K. True, medical care is expensive here, but then salaries are higher than elsewhere and the cost can be, and is in most cases, adequately covered by insurance. Medicaid takes care of the indigent and Medicare of the elderly. Legislation has already been passed which makes the Government responsible for the cost of dialysis and kidney transplantation, and finally legislation is pending for government funding of so-called catastrophic illness.

One could continue to enumerate many more positive aspects of American medicine, but Professor Witts must know that there are a great number of expatriate British doctors, and I am sure they would provide him with plenty of evidence to rebut what he reads in a book. I suggest, therefore, that Professor Witts comes here and sees for himself the state of American medicine before condemning us all on hearsay evidence.-I am, etc.,

\section{LANGDALE GREGORY} Norwich, N.Y.

\section{Haemophilus influenzae Apparently} Resistant to Trimethoprim

SIR,-Professor J. R. May and Mrs. Judith Davies (12 August 1972, p. 376) suggested that the incidence of strains of Haemophilus 